\title{
Poder político e propriedade da terra no terri- tório do Velho Chico, Bahia
}

Political power and land ownership in the territory of the Old São Francisco River, Bahia

A questão fundiária é um assunto que permeia a formação do território nacional. A má distribuição das terras no Brasil é consequência de um processo histórico que se inicia com a colonização. O território foi retalhado por latifúndios inertes, baldios e virgens, cujas sementes foram as sesmarias. A apropriação da terra, a maneira como ela se distribui e as condições de exploração estão associadas à estrutura fundiária. O espaço agrário brasileiro foi organizado em um contexto no qual a terra era sinônimo de poder e, em consequência disso, concentrava-se nas mãos de alguns poucos proprietários. Quinhentos anos depois, esse cenário se mantém. Tanto a formação do campo brasileiro foi marcada pela presença do latifúndio, quanto o grande proprietário desempenhou ou ainda tem desempenhado muitas vezes o papel de chefe político local, atuando segundo uma lógica paternalista, na qual a política é concebida e realizada como uma extensão da vida privada. A política aparece, em forte medida, como negócio privado das elites.

O Velho Chico, na sua conformação, foi o território de renomados coronéis, onde o fenômeno do coronelismo mais resistiu ao tempo e a concentração do poder político-econômico está diretamente vinculada à

É mestre em Economia pela Faculdade de Economia da Universidade Federal da Bahia (Salvador, BA). E-mail:minacarol@gmail.com.

** É professora da Faculdade de Economia da Universidade Federal da Bahia (Salvador, BA). E-mail: ggo@ufba.br. 
concentração da terra. A presença de grandes propriedades numa região baseada, principalmente, na atividade agropecuária, que tem a terra como elemento primordial de produção, pode indicar quem são os detentores do poder e quem são os excluídos. Há muito tempo a posse da terra servia para mensurar riqueza, indicar poder, não somente se associando ao sistema de produção - intensivo ou extensivo -, mas também como reserva de valor, gerando assim pouco emprego e renda.

Diante do exposto, este artigo tem por objetivo analisar a apropriação das terras no Território de Identidade do Velho Chico (TVC), no semiárido baiano, desde o início de sua formação e também nas formas de continuidade atuais, garantindo a concentração da posse da terra. A partir daí, busca-se entender as relações de propriedade da terra - como instrumento de poder regional - com o poder político.

A apresentação da discussão foi pensada, além desta introdução, em um tópico que caracterize o processo histórico de ocupação do espaço agrário brasileiro. A seguir, trata-se do processo de formação e da situação socioeconômica do TVC. Posteriormente, são discutidos os aspectos relacionados com a propriedade da terra e sua relação com o poder político na região. Por fim, são elencadas as considerações resultantes deste estudo.

\section{Espaço agrário brasileiro: ocupação e função social da terra}

A história territorial do Brasil começa em Portugal, e é nesse "pequeno reino peninsular", na história de suas instituições territoriais, entre as quais a das sesmarias - tronco de que se ramificou a propriedade imóvel -, que serão encontradas as origens remotas do regime de terras brasileiro (Lima, 2002). O regime de sesmarias desenvolveu-se no Brasil durante o período de 1530 a 1822. Instituído o regime de capitanias hereditárias em 1534, o instrumento legal para a distribuição das terras foi a Lei das Sesmarias.

$\mathrm{Na}$ colônia, as sesmarias não funcionavam como na metrópole, havendo alguns desvirtuamentos ${ }^{1}$ com o benefício de apenas uma minoria; seu objetivo era acelerar o processo de colonização da América portuguesa. Os

\footnotetext{
A chamada Lei de Sesmarias, de 1375, aplicada em Portugal, tinha como princípio uma política de reestruturação do sistema fundiário no país, fixando os trabalhadores à terra com o objetivo de estimular a produção. O modelo adotado em Portugal limitava o tempo de concessão da terra. Já no Brasil, as sesmarias foram concedidas em caráter perpétuo, contrariando o texto régio que estabelecia que a doação seria apenas vitalícia. Com relação à dimensão da sesmaria, a legislação nada estabelecia - e no Brasil, em geral, tinham grandes dimensões.
} 
sesmeiros tinham um prazo-limite de cinco anos para cultivar as terras, podendo perdê-las em caso de descumprimento da legislação. Algumas concessões de terras foram feitas para a construção de engenhos de açúcar e estabelecimentos semelhantes - de onde se originaram os futuros senhores de engenho e os grandes latifúndios. As concessões de sesmarias restringiam-se aos candidatos a latifundiários e nada mais eram do que uma distribuição compulsória em benefício da agricultura (Lima, 2002).

Com a extinção das sesmarias em 1822, a posse disseminou-se livremente, passando a abranger fazendas inteiras. Se as sesmarias formavam verdadeiros latifúndios, o mesmo se seguiu com as posses, pois nem sempre estas serviram à pequena propriedade, uma vez que delas também se constituíram latifúndios. "A humilde posse com cultura efetiva, cedo, se impregnou do espírito latifundiário que a legislação das sesmarias difundira e fomentara" (Lima, 2002, p. 58). A tendência para a grande propriedade já estava arraigada. Extinto o regime de sesmarias, a posse passou a servir-lhe de veículo, e as compras e vendas das posses manifestadamente irregulares se multiplicaram.

Em meados do século XIX, visando consolidar o poder dos proprietários e abrir perspectivas aos estrangeiros que eram atraídos para o Brasil, estabeleceu-se o acesso a terra através do contrato de compra e venda, com Lei de Terras de 1850, consolidando-se o poder dos latifundiários (Andrade, 2002). Essa lei procurava ajustar todos os costumes referentes à posse, mas o que de fato pretendia era regularizar a propriedade privada da terra, definindo aos poucos o quadro agrário brasileiro (Taglietti, 2005). Dessa forma, a aprovação da lei foi uma tentativa de organizar as doações de terras feitas desde o início do processo de colonização, de regularizar as áreas ocupadas depois de 1822 e de incentivar a vinda de imigrantes para o Brasil.

A Lei de Terras, como ficou conhecida a Lei n. 601 de 1850, embora reconhecesse a aquisição da propriedade pela posse, cuidou de corrigir alguns excessos desse particular. Com ela terminou o regime legal das posses no Brasil e ficou proibida a aquisição de terras devolutas por outro título que não fosse o de compra. A aquisição direta das terras devolutas por particulares ficou vedada, firmando-se a exclusividade dos direitos do Estado sobre as terras desocupadas. As terras não ocupadas só poderiam ser adquiridas através da compra nos leilões mediante pagamento à vista, e não mais através da posse - meio que passou a ser criminalizado. As terras já ocupadas, por sua vez, podiam ser regularizadas como propriedade privada. Em relação às 
posses irregulares, a lei teve de abrir um precedente prevendo que os sesmeiros em situação irregular e os posseiros se transformariam em proprietários de pleno direito de uso, mas não de venda da terra.

É notório que a Lei de Terras regulamentou a questão agrária, mas, também, que iniciou um processo de expropriação rural, na medida em que estabelecia que a aquisição de terras públicas se desse através da compra (Taglietti, 2005). Seu efeito prático foi dificultar a formação de pequenos proprietários, já que estes não dispunham de recursos para adquirir uma propriedade e liberar a mão de obra para os grandes fazendeiros. Dessa forma, muitos tiveram o acesso a terra barrado por condições econômico-financeiras e, sem opções, migraram para centros urbanos. Aqueles que continuaram no campo, como posseiros, permaneceram ou em situação de ilegalidade, sem direito ao título de propriedade, ou como mão de obra para a grande propriedade.

Durante o período de colonização e ocupação do território brasileiro não houve mecanismos para impedir a concentração de terras e, como consequência, a organização do espaço agrário era também a organização do poder. "O tamanho da propriedade e o poder político-econômico do proprietário definiam sua função e determinavam a implantação de estruturas que viabilizassem a produção" (Andrade, 2002, p. 15).

Em uma sociedade capitalista, da qual a acumulação e a apropriação dos meios de produção por uma minoria são fundantes, a propriedade apresenta grande importância sob a ótica da produção. "Os ideais das revoluções liberais europeias conferiram à propriedade caráter absoluto, perpétuo e exclusivo" (Almeida, 2009, p. 1). Essa concepção só começou a ser alterada após a Segunda Guerra Mundial com o Estado de bem-estar social ${ }^{2}$. Ao se atribuir nova relevância e condições à natureza do direito de propriedade, esta é relativizada. $\mathrm{O}$ conceito de propriedade recebe um sentido mais amplo, não apenas essencialmente econômico como outrora; passa a ser analisado como riqueza destinada à produção de bens que satisfaçam às necessidades sociais; a acolher o papel de utilidade à sociedade e não apenas ao interesse particular. O proprietário passa a ter o uso da propriedade condicionado ao bem-estar social, não podendo, portanto, incidir em atos configuradores do abuso de direito de propriedade (Almeida, 2009).

Nesse tipo de organização político-social, desenvolvida principalmente na Europa, o Estado deve atuar como agente indutor da promoção social e organização da economia, buscando garantir serviços públicos e proteção à população. De acordo com Cancian (2007), o Brasil nunca chegou a estruturar um Estado de bem-estar semelhante aos dos países desenvolvidos. 
Nos termos da Constituição Brasileira de 1988, "pesa sobre a propriedade uma hipoteca: o cumprimento da função social” (Hackbart, 2008, p. 16), isto é, o cumprimento simultâneo dos aspectos, econômico, ambiental, trabalhista e do bem-estar social. A propriedade não é mais absoluta; o que é absoluto é o cumprimento de sua função social (Hackbart, 2008). A utilização da propriedade, antes feita somente para benefício próprio e sem que se levassem em conta os efeitos do processo produtivo sobre os recursos naturais e tão pouco aos valores sociais, passa a requerer o atendimento a coletividade. Além de pensar na produtividade, busca-se o respeito ao meio ambiente e às relações de trabalho. Como dispõe a doutrina da função social da propriedade, estabelecida pela Lei 4.504/1964 - o Estatuto da Terra (Brasil, 1964):

Art. $2^{\circ}$ - É assegurada a todos a oportunidade de acesso à propriedade da terra, condicionada pela sua função social, na forma prevista nesta Lei.

$\$ 1^{\circ}$ A propriedade da terra desempenha integralmente a sua função social quando, simultaneamente:

a) favorece o bem-estar dos proprietários e dos trabalhadores que nela labutam, assim como de suas famílias;

b) mantém níveis satisfatórios de produtividade;

c) assegura a conservação dos recursos naturais;

d) observa as disposições legais que regulam as justas relações de trabalho entre os que a possuem e a cultivem.

Contudo, quem são os "todos" de que trata o artigo, já que os que detêm o acesso à terra são a minoria? De acordo com Germani (2006, p. 140), o estatuto: “[...] pouco ou quase nada contribuiu para modificar a estrutura de posse da terra rural na perspectiva de uma melhor distribuição. Ao contrário, neste último período a concentração da propriedade tendeu a agravar-se, intensificou-se o êxodo rural, e se multiplicaram os conflitos armados pela posse da terra".

A Lei 4.504/1964 (Estatuto da Terra), que regulamenta os direitos e as obrigações referentes aos bens imóveis rurais para os fins de execução da reforma agrária e de promoção da política agrícola, tem reforçada na Constituição de 1988, no artigo 184, como competência da União desapropriar por interesse social, visando a reforma agrária, o imóvel rural que não cumpra sua função social. A Constituição de 1988 ressalta ainda a relevância do Estatuto ao ratificar o cumprimento da função social da propriedade rural: 
Art. $9^{\circ}$ - A função social é cumprida quando a propriedade rural atende, simultaneamente, segundo graus e critérios estabelecidos nesta lei, os seguintes requisitos: I - aproveitamento racional e adequado;

II - utilização adequada dos recursos naturais disponíveis e preservação do meio ambiente;

III - observância das disposições que regulam as relações de trabalho;

IV - exploração que favoreça o bem-estar dos proprietários e dos trabalhadores.

Ainda de acordo com a Carta Magna, a propriedade que não cumprir sua função social deve ser desapropriada. O princípio da função social da propriedade permanece até hoje sem ter a devida eficácia, pois, entre outros fatores, a defesa absoluta da propriedade continua prevalecendo em detrimento de critérios como o aproveitamento racional e adequado dos recursos naturais, a preservação do meio ambiente e o não atendimento às condições de trabalho.

Nesse contexto de utilização e domínio das terras, Caio Prado Jr. (1979) lembra que a grande exploração de tipo comercial tende, quando a conjuntura lhe é favorável, a se expandir e a absorver terras aproveitáveis, eliminando lavradores independentes, proprietários ou não, bem como suas culturas de subsistência. Em consequência, agravam-se as condições de vida da população trabalhadora rural cuja remuneração, seja em salário, seja em participação no produto principal, está sempre aquém do preço relativo dos gêneros de subsistência que os trabalhadores são obrigados a adquirir no comércio.

A função social da terra estará cumprida quando um maior número de pessoas tiver acesso a terra, para nela viver e trabalhar; quando essa terra produzir alimentos suficientes para alimentar um maior número de pessoas na sociedade, ao mesmo tempo conservando os recursos naturais, prezando as relações de trabalho e visando o bem-estar de todos.

\section{O território do Velho Chico}

De acordo com Abramovay e Beduschi Filho (2004), na década de 1990, o planejamento brasileiro - ao passar da lógica de repartição setorial de recursos para uma lógica territorial - teve sua ação governamental pautada em programas, no estabelecimento de organizações locais e na adoção de novos recortes do território nacional. Tais iniciativas, segundo os autores, 
pretendiam planejar o processo de desenvolvimento com base em recortes territoriais que não se limitassem às cinco regiões políticas em que se organiza o país.

Dentro da perspectiva da abordagem territorial, com o objetivo de identificar oportunidades de investimento e prioridades temáticas definidas a partir da realidade local de cada território, o governo da Bahia - apoiado pela política de desenvolvimento territorial do governo federal em 2007 - estabeleceu um foco territorial baseado em 27 territórios de identidade, constituídos a partir do arranjo espacial federal.

Um desses 27 territórios de identidade é o TVC, que é composto por dezesseis municípios, sendo eles: Barra, Bom Jesus da Lapa, Brotas de Macaúbas, Carinhanha, Feira da Mata, Ibotirama, Igaporã, Malhada, Matina, Morpará, Muquém do São Francisco, Oliveira dos Brejinhos, Paratinga, Riacho de Santana, Serra do Ramalho e Sítio do Mato.

O TVC acompanha o leito do rio São Francisco, que o atravessa e o divide de sul a norte. Limita-se a oeste com os territórios de identidade da Bacia do Rio Corrente e do Oeste Baiano; a leste com Irecê, Chapada Diamantina, Bacia do Paramirim e Sertão Produtivo; ao norte com o Sertão do São Francisco; ao sul com o estado de Minas Gerais - como se vê na Figura 1.

Em sua totalidade, o Velho Chico está inserido no semiárido nordestino. É marcado por irregularidades no regime de chuvas e por solos areno-argilosos - pobres em nutrientes - com risco de salinização de médio a alto, características inerentes à região semiárida. A vegetação do TVC é dos tipos cerrado e caatinga, com o predomínio da última. As condições adversas do TVC condicionam fortemente os povos do território a sobreviver principalmente de atividades econômicas ligadas à agricultura e à pecuária.

O TVC apresenta uma área de $46.328,39 \mathrm{~km} 2$, correspondendo a $8,2 \%$ da área total do estado da Bahia. Em 2000, a população total era de 349.689 habitantes, sendo 57,49\% habitantes da área rural e 42,51\% de população urbana. Em 2010, a população total era de 370.095 habitantes, com 53,41\% na área rural e 46,59\% da área urbana (IBGE, 2010). Embora não tenha havido um aumento significativo da população total, houve uma tendência de urbanização, ainda que a população continue concentrada nas áreas rurais. Bom Jesus da Lapa, Feira da Mata, Ibotirama, Igaporã, Morpará e Sítio do Mato são os únicos municípios do TVC com população mais concentrada em áreas urbanas, com $68 \%, 52 \%, 77 \%, 52 \%, 67 \%$ e $57 \%$, respectivamente (IBGE, 2010). 
Brotas de Macaúbas, Feira da Mata, Morpará e Serra do Ramalho apresentaram redução no número de habitantes de 2000 a 2010, por causa, entre outros fatores, do êxodo rural, devido sobretudo à busca de melhores condições de vida.

Figura 1 - Território de Identidade do Velho Chico, Bahia.

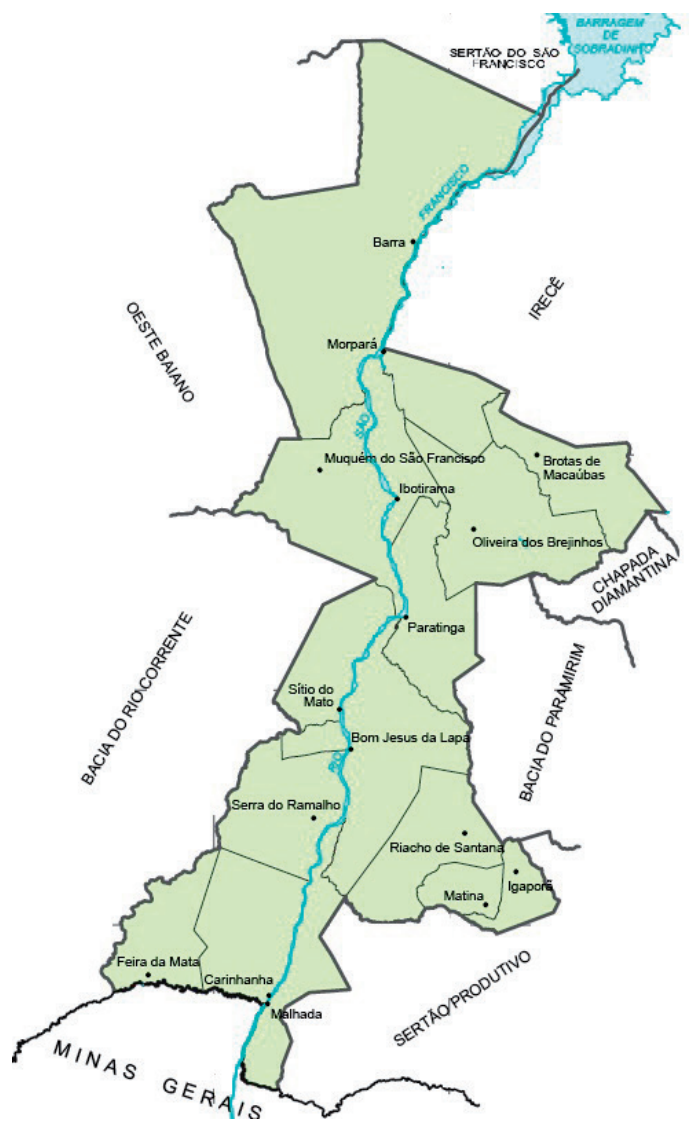

Fonte: Conferência de Cultura (2011).

Com relação à participação do valor adicionado dos setores da economia, entre os anos de 2006 e 2009, os setores de serviços e agropecuário permaneceram com maior participação na economia do TVC, representando $56 \%$ e $19 \%$, respectivamente, de seu produto interno bruto (PIB). Em 2009, todos os municípios do território tiveram maior arrecadação do setor de serviços. 
No período de análise, a indústria diminuiu sua participação no PIB de 10\%, em 2006, para 9\%, em 2009. Bom Jesus da Lapa possui o PIB mais expressivo do Velho Chico, R\$ 351 milhões, aproximadamente - trata-se de uma exceção, sendo considerado um polo de desenvolvimento: é o município com maior presença de perímetros irrigados do TVC, no qual se concentra o maior volume de investimentos e a melhor infraestrutura urbana (Germani, Olalde e Oliveira, 2006). Assim como Bom Jesus da Lapa, Barra, Riacho de Santana e Serra do Ramalho também figuram entre os municípios com o PIB mais expressivo da região.

O Velho Chico pode ser visto como um território com pequena participação no produto econômico do Estado: seu PIB representou apenas 1,1\% do total do Estado, em 2009. Para o mesmo ano, quando comparado ao ano de 2006, o PIB do TVC apresentou uma taxa de crescimento de 42,41\% contra $42,02 \%$ da Bahia.

A renda per capita ${ }^{3}$ tem sido muito baixa em todos os municípios que integram o território e é inferior à média baiana. Em 2005 houve uma maior aproximação entre a renda per capita do TVC com a da Bahia; todavia, de 2006 a 2009, a diferença foi aumentando até alcançar R\$5.491,19, em 2009. A renda per capita estadual cresceu, enquanto a do TVC não conseguiu ultrapassar a casa dos $\mathrm{R} \$ 4$ mil. $\mathrm{O}$ valor estimado da renda per capita não garante que haja condições de vida igualitária para a população, já que se evidencia a presença de taxas significativas de pobreza nos municípios.

O uso de indicadores pode dar uma dimensão de como a população vive. Dos dezesseis municípios do TVC, em 1991, oito possuíam índice de desenvolvimento humano municipal (IDHM) baixo, de acordo com o Programa das Nações Unidas para o Desenvolvimento (PNUD). Em 2000, constatou-se uma relativa melhora nos índices e uma maior aproximação do IDHM do TVC com o estado da Bahia. Ibotirama apresentou o maior IDHM do TVC, quase 0,70 , classificado como médio desenvolvimento. No geral, o TVC apresenta índices muito baixos de desenvolvimento, principalmente no que se refere ao subíndice da renda. Em 1991, Serra do Ramalho apresentou o menor IDH-renda, 0,378, ainda que tenha se elevado em 2000;

O PIB per capita é o indicador que pode ser utilizado para mensurar a renda. A renda per capita é o resultado da soma de tudo que é produzido em uma nação no ano por pessoa, corresponde ao valor das riquezas que caberia a cada pessoa, ou seja, à renda média da população. No entanto, mesmo a renda per capita sendo elevada, muitas vezes não confirma ou não reflete a realidade, pois de forma geral a renda é mal distribuída. 
todavia, 75\% dos municípios do TVC ainda apresentam baixo desenvolvimento nesse subíndice.

\section{Caracterização fundiária e formas de acesso a terra no Velho Chico}

Para compreender a estrutura fundiária de uma área, região ou país, deve-se buscar entender a forma como as suas propriedades rurais estão organizadas, isto é, seu número, tamanho e distribuição social. A desigualdade na distribuição da terra é um fator determinante para o desempenho dos dados vistos anteriormente.

A concentração da terra pode ser medida através do cálculo do índice de Gini, indicador que mede o grau de concentração de um bem - no caso, a terra. Ele varia num intervalo de zero a um, sendo que quanto mais próximo de um, maior é a desigualdade na distribuição e, quanto mais próximo de zero, menor ela ét.

Neste contexto, observa-se, no Quadro 1 que, de uma forma geral o histórico dos municípios do TVC é de concentração.

De acordo com os dados de 2006, dos dezesseis municípios do TVC, nove apresentam um grau de concentração de "forte a muito forte", com destaque para os municípios de Barra, Muquém do São Francisco e Malhada, com 0,906, 0,886 e 0,876, respectivamente (Projeto GeografAR, 2008). No outro extremo, Serra do Ramalho tem um índice de 0,463 , concentração que segundo a classificação é de "fraca a média".

É relevante notar que o município de Serra do Ramalho originou-se do assentamento das famílias atingidas com a construção da barragem de Sobradinho, a partir da criação do Projeto Especial de Colonização (PEC) implantado em 1975, tendo se emancipado e se tornado município apenas em 1989. Por sua ocupação ter sido estabelecida em partes iguais para cada família, seus dez anos de emancipação já apontavam para uma tendência de concentração da propriedade da terra (Germani, Olalde e Oliveira, 2006). Contudo, outros municípios tão jovens quanto Serra do Ramalho, mas com origens distintas, têm grau de concentração ainda mais elevado como: Feira da Mata (0,690), Matina $(0,705)$ e Sítio do Mato $(0,724)$.

\footnotetext{
4 A classificação do grau de concentração adotada neste artigo é a de Lourival Câmara (1949), que considera intervalos de valores do índice de Gini, sendo: de 0 a 0,1, concentração nula; 0,101 a 0,250, nula a fraca; 0,251 a 0,5, fraca a média; 0,501 a 0,700, média a forte; 0,701 a 0,9, forte a muito forte; e, 0,901 a 1, concentração muito forte a absoluta.
} 
Quadro 1 - Evolução histórica do índice de Gini (TVC, 1920-2006)

\begin{tabular}{|c|c|c|c|c|c|c|c|c|c|c|}
\hline Municípios & 1920 & 1940 & 1950 & 1960 & 1970 & 1975 & 1980 & 1985 & 1996 & 2006 \\
\hline Barra & 0,962 & 0,834 & 0,944 & 0,928 & 0,918 & 0,934 & 0,954 & 0,955 & 0,959 & 0,906 \\
\hline $\begin{array}{c}\text { Bom Jesus da } \\
\text { Lapa }\end{array}$ & 0,982 & 0,644 & 0,936 & 0,594 & 0,846 & 0,904 & 0,812 & 0,841 & 0,875 & 0,792 \\
\hline $\begin{array}{l}\text { Brotas de } \\
\text { Macaúbas }\end{array}$ & 0,896 & 0,387 & 0,615 & 0,549 & 0,530 & 0,659 & 0,645 & 0,664 & 0,591 & 0,626 \\
\hline Carinhanha & 0,990 & 0,734 & 0,822 & 0,734 & 0,611 & 0,661 & 0,719 & 0,750 & 0,667 & 0,633 \\
\hline Feira da Mata & & & & & & & & & 0,769 & 0,690 \\
\hline Ibotirama & & & & 0,862 & 0,876 & 0,860 & 0,860 & 0,866 & 0,837 & 0,818 \\
\hline Igaporã & & & & 0,551 & 0,599 & 0,608 & 0,638 & 0,643 & 0,702 & 0,713 \\
\hline Malhada & & & & & 0,802 & 0,848 & 0,854 & 0,899 & 0,910 & 0,876 \\
\hline Matina & & & & & & & & & 0,710 & 0,705 \\
\hline Morpará & & & & & 0,665 & 0,739 & 0,765 & 0,719 & 0,854 & 0,728 \\
\hline $\begin{array}{c}\text { Muquém do } S \text {. } \\
\text { Francisco }\end{array}$ & & & & & & & & & 0,885 & 0,886 \\
\hline $\begin{array}{c}\text { Oliveira dos } \\
\text { Brejinhos }\end{array}$ & 0,977 & 0,621 & 0,783 & 0,686 & 0,671 & 0,755 & 0,810 & 0,792 & 0,745 & 0,766 \\
\hline Paratinga & & & 0,783 & 0,611 & 0,623 & 0,793 & 0,767 & 0,748 & 0,651 & 0,558 \\
\hline $\begin{array}{l}\text { Riacho de } \\
\text { Santana }\end{array}$ & 0,964 & 0,662 & 0,731 & 0,635 & 0,618 & 0,659 & 0,677 & 0,766 & 0,780 & 0,707 \\
\hline $\begin{array}{l}\text { Serra do } \\
\text { Ramalho }\end{array}$ & & & & & & & & & 0,410 & 0,463 \\
\hline Sítio do Mato & & & & & & & & & 0,928 & 0,724 \\
\hline TVC & 0,962 & 0,647 & 0,802 & 0,683 & 0,705 & 0,765 & 0,773 & 0,786 & 0,767 & 0,724 \\
\hline Bahia & 0,734 & 0,784 & 0,794 & 0,779 & 0,795 & 0,805 & 0,821 & 0,835 & 0,829 & 0,838 \\
\hline
\end{tabular}

Fonte: Projeto GeografAR (2010).

No TVC, verifica-se que 62,5\% dos municípios possuem um grau de concentração de "forte a muito forte". Na categoria de "muito forte a absoluta" o TVC (6,25\%) também é superior ao do estado (3,61\%), reforçando a ideia de que a terra está especialmente concentrada na região de estudo.

O número de estabelecimentos familiares no TVC é bastante superior $(88,64)$ quando comparado ao de outros tipos. Em relação à área, as outras 
propriedades ocupam 55,5\%, enquanto as familiares ocupam $45,5 \%$. Em termos de valor bruto da produção, as propriedades familiares contribuem com mais de 50\%, participação superior à observada no estado todo, que é de $39,88 \%$. Por fim, quanto ao número de pessoal ocupado, a agricultura familiar emprega quase $90 \%$, enquanto que a agricultura patronal emprega somente $10 \%$, aproximadamente.

A análise dos dados revela a importância da agricultura familiar no TVC, tanto pelo grande número de estabelecimentos quanto pela participação bastante elevada no valor da produção, visto o tamanho da área reservada a ela. Com isso, pode-se inferir que a produção patronal no TVC se comporta de forma extensiva, servindo a terra muitas vezes somente como reserva de valor, gerando pouco emprego e renda.

O TVC possui um mosaico de formas de acesso a terra. Dentre as identificadas, encontram-se os assentamentos derivados da ação do Estado - projeto de colonização, projetos de reforma agrária, o Projeto Cédula da Terra $(\mathrm{PCT})$ e o Projeto Crédito Fundiário de Combate à Pobreza Rural (PCF) ${ }^{5}$ -, as comunidades tradicionais - quilombolas e de fundo de pasto - e os acampamentos e comunidades indígenas (Quadro 2).

Hoje, o TVC tem 57 projetos de assentamento (PAs) de reforma agrária, com destaque para Sítio do Mato, com treze. É importante ressaltar que esse município apresentou, no último Censo, um grau de concentração de terras de 0,724 de acordo com o índice de Gini, classificado como "forte a muito forte".

Outra forma de acesso a terra encontrada no TVC são os assentamentos. Houve, no passado, nove assentamentos do PCT - que vigorou de 1997 a 2002, quando essa primeira fase foi concluída. O programa teve continuidade então através do PCF, implantado em 2002 com o apoio do Banco Mundial. Esse programa, que tem sete assentamentos no TVC, é entendido como uma antirreforma agrária, em que o acesso à terra não se dá pelo instrumento de desapropriação, mas pelo de compra e venda da terra, financiada pelo sistema bancário e intermediada pelo Estado (Germani, Olalde e Oliveira, 2006).

Além dos assentamentos derivados da ação do Estado, encontram-se aqueles oriundos do processo histórico de ocupação da terra e da orga-

A implantação do PCT na Bahia ocorreu na esteira de outros programas do Banco Mundial voltados para a área rural do Nordeste brasileiro (Sauer e Pereira, 2006). 
nização, como, por exemplo, as comunidades negras rurais quilombolas e de fundo de pasto. As primeiras estão vinculadas à lógica de resistência secular desenvolvida pelas comunidades tradicionais marginalizadas pela sociedade brasileira. A presença de negros na região é tida como originária de escravos - que fugiam para o interior, subtraindo-se a sua condição de mão de obra forçada - oriundos dos quilombos espalhados pelos sertões nordestinos (Germani, Olalde e Oliveira, 2006). No TVC, até o momento, cerca de 69 comunidades negras rurais quilombolas foram identificadas. Todavia, a expectativa é de que existam diversas outras comunidades ainda não identificadas.

A denominação "fundo de pasto" passou a existir quando o governo da Bahia, a partir de 1983, reconheceu juridicamente essa forma de organização social. "Os fundos de pasto estão localizados em sua totalidade nas regiões onde prevalece o clima semiárido, convivendo com a caatinga e a escassez de água” (Germani, Olalde e Oliveira, 2006, p. 138). Apenas três municípios do TVC possuem comunidades identificadas como fundos de pasto: Barra (1), Brotas de Macaúbas (3) e Oliveira dos Brejinhos (11). Nessas comunidades, cada família possui uma unidade produtiva de produção coletiva, permitindo a circulação dos animais.

Por fim, outra forma de acesso a terra são os acampamentos de trabalhadores rurais sem-terra, que "são considerados expressões da luta pela terra, da materialização dessa luta no espaço no território" (Germani, Olalde e Oliveira, 2006, p. 123). Esses trabalhadores, muitas vezes em movimentos sociais, ao ocupar uma fazenda ou terras devolutas representam a pressão da sociedade civil sobre o Estado para a efetivação de suas demandas (Germani, Olalde e Oliveira, 2006). Não obstante as dificuldades de registros precisos, foram identificados 28 acampamentos de sem-terra no TVC.

As comunidades indígenas identificadas no TVC localizam-se em três municípios: em Ibotirama encontra-se o povo tuxá; em Muquém do São Francisco, os pankarus e os kiriris; em Serra do Ramalho, os pankarus.

A diversidade de formas de acesso a terra identificada no TVC demonstra a riqueza de que dispõe o território em função de sua conformação, o que, por sua vez, mostra ao mesmo tempo sua singularidade e o processo complexo que envolve o acesso a terra no território. 
Quadro 2 - Formas de acesso a terra identificadas (TVC, 2010)

\begin{tabular}{|c|c|c|c|c|c|c|c|}
\hline municípios & $\begin{array}{l}\text { comunidades } \\
\text { quilombolas }\end{array}$ & $\begin{array}{c}\text { PA } \\
\text { Reforma } \\
\text { Agrária }\end{array}$ & $\begin{array}{l}\text { acampa- } \\
\text { mentos }\end{array}$ & $\begin{array}{c}\text { fundo de } \\
\text { pasto }\end{array}$ & $\begin{array}{c}\text { projeto } \\
\text { Cédula da } \\
\text { Terra }\end{array}$ & $\begin{array}{l}\text { projeto } \\
\text { Crédito } \\
\text { Fundiário }\end{array}$ & indígenas \\
\hline Barra & 8 & 10 & 3 & 1 & 1 & 3 & \\
\hline $\begin{array}{c}\text { Bom Jesus da } \\
\text { Lapa }\end{array}$ & 16 & 9 & 1 & & 1 & & \\
\hline $\begin{array}{l}\text { Brotas de } \\
\text { Macaúbas }\end{array}$ & & & & 3 & & & \\
\hline Carinhanha & 10 & 9 & 2 & & & & \\
\hline Feira da Mata & & & 4 & & & & \\
\hline Ibotirama & & 1 & 5 & & 2 & 1 & 1 \\
\hline Igaporã & 10 & & & & & & \\
\hline Malhada & 4 & 2 & 4 & & & & \\
\hline Matina & & & & & 1 & & \\
\hline Morpará & & 1 & & & 2 & & \\
\hline $\begin{array}{c}\text { Muquém do S. } \\
\text { Francisco }\end{array}$ & 3 & 4 & 3 & & 1 & 2 & 1 \\
\hline $\begin{array}{l}\text { Oliveira dos } \\
\text { Brejinhos }\end{array}$ & & 1 & & 11 & & & \\
\hline Paratinga & & 4 & 2 & & & & \\
\hline $\begin{array}{l}\text { Riacho de } \\
\text { Santana }\end{array}$ & 13 & 1 & & & 1 & 1 & \\
\hline $\begin{array}{l}\text { Serra do } \\
\text { Ramalho }\end{array}$ & & 2 & & & & & 1 \\
\hline Sítio do Mato & 5 & 13 & 4 & & & & \\
\hline Total & 69 & 57 & 28 & 15 & 9 & 7 & 3 \\
\hline
\end{tabular}

Fonte: Projeto GeografAR (2010, adaptado).

\section{Poder político e trajetória político-partidária no Velho Chico}

Para conhecer a vida política do interior nordestino é necessário entender o fenômeno do coronelismo, surgido quando o regime político ainda era monárquico e institucionalizado com a criação da Guarda Nacional na primeira metade do século XIX, mas existente ainda no decorrer do período republicano. Leal (1976, p. 20) define o coronelismo como uma "forma peculiar de manifestação do poder privado”, um sistema político da Primeira 
República dominado por uma relação de compromisso entre os senhores donos de terras em decadência e o poder público fortalecido. A partir desse compromisso, de acordo com o autor, resultam as características secundárias do sistema coronelista, como o mandonismo, o filhotismo, o falseamento do voto e a desorganização. O coronelismo começou a declinar a partir de 1930, com o aperfeiçoamento do processo eleitoral, com a produção industrial e a crise do café, com o aumento da população e do eleitorado urbano e com a expansão dos meios de comunicação e transportes (Leal, 1976).

Tanto Leal (1976) como Souza (1998) consideram a propriedade da terra um dos fatores determinantes do coronelismo. Para Souza (1998, p. 24), “[...] não se pode desvincular o coronelismo da posse da terra, do mesmo modo que não pode enxergar o coronel sem os cabras, sem os jagunços, sem as relações que se denominam largamente de semifeudais, sem o prestígio e o mando político, quer em sua área de influência ou exercendo liderança sobre os demais coronéis de uma região". O autor aponta outro aspecto a respeito da propriedade de terras que evidencia que o coronel não era apenas proprietário de terras -havia coronéis em outras posições sociais, como o coronel-comerciante e o coronel-industrial -, sendo antes "um senhor de homens que a seu mando estão empunhando armas. É o chefe político de uma cidade, grande comerciante, monopolizador" (Souza, 1998, p. 24).

A imensidão dos sertões isolava os povos. Para chegar ao interior, "as providências do governo tinham de ceder às dificuldades do meio" (Souza, 1998, p. 18). A ausência quase absoluta da ação do poder público contribuiu muito para preservar a ascendência dos coronéis. Era o coronel quem exercia as mais variadas funções, sendo simultaneamente o detentor do poder político, jurídico e legislativo no município que lhe cabia: "Daí se pode dizer que o coronelismo prosperou à sombra da inoperância dos governos" (Souza, 1998, p. 18).

Na região do rio São Francisco, o município de Barra teve chefes pacatos em que "[...] dominou por mais de um século a família Mariani, sem truculência, sem barulhos, sendo de se notar que os dominadores promoviam a alfabetização do povo, mandavam filhos para as academias, para o seminário" (Souza, 1998, p. 19).

Outro aspecto importante do coronelismo é o sistema de reciprocidade, onde de um lado havia o prestígio - próprio dos coronéis - e, de outro lado o prestígio de empréstimo que o poder público lhes conferia (Leal, 1976). 
Por causa da liderança exercida pelo coronel, o governo se sentia obrigado a um tratamento de reciprocidade, sem a qual não havia por que existir a relação. A fonte do poder político de um coronel era medida tanto por sua base econômica como por sua força eleitoral: "A força eleitoral empresta-lhe prestígio político, natural coroamento de sua privilegiada situação econômica e social de dono de terras" (Leal, 1976, p. 23). Perder o apoio do Estado era o pior mal que podia acontecer ao chefe político municipal.

O coronelismo, predominantemente no Nordeste, teve sua origem na propriedade da terra. Ao longo dos anos, como fenômeno social, foi se transformando, recuando e cedendo espaço a novas formas de lideranças oriundas de profissões liberais, industriais ou comerciantes prósperos -, o que não significa que tenha acabado; o coronel pode ter se tornado doutor, e a fazenda se transformado em fábrica.

De acordo com Bursztyn (1984), há uma importante modificação na sociedade local, pois o papel de mediador entre o Estado e o povo é transferido dos coronéis para os funcionários, que materializam o caráter assistencial e paternalista do Estado no âmbito local. Ao contrário do coronel tradicional, o novo coronel - o funcionário - é mais dinâmico em termos de comportamento capitalista. Dessa forma, o fenômeno do coronelismo persiste na figura dos líderes locais com capacidade de persuadir, conquistar ou convencer o eleitorado de que são bondosos, honestos, generosos e os mais preparados para assumir os destinos de determinadas localidades.

Entendido o contexto em que se desenvolveu o fenômeno do coronelismo, antes de tratar da trajetória político-partidária do TVC, analisamos a evolução dos partidos políticos brasileiros e seus desdobramentos na formação de novas legendas, que teve como base os principais acontecimentos históricos e fatos políticos que marcaram o cenário político-partidário nacional. Essa análise foi feita a partir do momento em que ocorre a Revolução de 1930 movimento que traçava novas diretrizes políticas para a época - e o fim da Primeira República (1889-1930).

O período de 1930 a 1945, a Era Vargas, é marcado por diversos acontecimentos ligados ao processo eleitoral, entre os quais a criação da Justiça Eleitoral, em 1932, que instituiu o voto secreto ${ }^{6}$ e o voto feminino - as mulheres passaram então a poder votar e serem votadas. O ano de 1937

Antes da Revolução de 1930 o voto de cabresto sustentava o regime político, como observado na seção anterior. 
foi marcado por tensões, e o golpe criou um hiato na história partidária do país. Surgia uma "nova ordem": o Estado Novo. Outorgada a Constituição de 1937, que extinguiu a Justiça Eleitoral, houve a abolição dos partidos políticos existentes, a suspensão das eleições livres e o estabelecimento de eleições indiretas para presidente da República, com mandato de seis anos.

Passada a turbulência do Estado Novo, a derrubada de Vargas, em 1945, dá início ao processo de reabertura política e de redemocratização. O primeiro partido político a surgir foi a União Democrática Nacional (UDN), criada em 1945, que representava a oposição liberal a Vargas. Nesse mesmo ano foram lançados o Partido Social Democrático (PSD) e o Partido Trabalhista Brasileiro (PTB), além de haver também a legalização do Partido Comunista Brasileiro (PCB), o que tornava claro o pluripartidarismo. Em 1946 foi promulgada uma nova Constituição.

Em 1964 é instaurado o regime militar, marcado pelo autoritarismo, pela supressão dos direitos constitucionais, pela censura, prisão e perseguição política. De acordo com Castilho (2012, p. 104), “o medo da reforma agrária foi um dos deflagradores do golpe militar, em 1964 - que criou no ano seguinte, o sistema bipartidário". Em 1965, é instaurado o bipartidarismo pelo Ato Institucional n. 2 (AI-2). Surgem, então, a Aliança Renovadora Nacional (Arena), que dependia do regime militar, e o Movimento Democrático Brasileiro (MDB), que tinha permissão para fazer oposição ao regime militar.

O fim da década de 1970 e o início dos anos de 1980 foram marcados pelo rompimento do bipartidarismo, com a extinção da Arena e do MDB e o retorno do pluripartidarismo. A Arena foi rebatizada de Partido Democrático Social (PDS), posteriormente Partido Progressista Renovador (PPR), Partido Progressista Brasileiro (PPB), até se chamar, atualmente, Partido Progressista (PP). O MDB transformou-se em Partido do Movimento Democrático Brasileiro (PMDB).

A Reforma Partidária de 1979 abriu perspectivas para novos agrupamentos com maior diferenciação em termos de representação. Surgem partidos vinculados a trabalhadores e segmentos das camadas médias, como o Partido dos Trabalhadores (PT) e o Partido Democrático Trabalhista (PDT). Outros partidos, vinculados a empresários e a elites tradicionais e modernas surgiram através de dissidências internas e externas nos partidos existentes: Partido da Social Democracia Brasileira (PSDB), em 1989; Partido da Frente Liberal (PFL), em 1985, extinto e refundado em 2007 como Democratas (DEM); 
Partido Liberal (PL), em 1985, atual Partido da República (PR), criado em 2006 da fusão entre o PL e o Partido de Reedificação da Ordem Nacional (Prona). Na Figura 1 podem-se observar os desdobramentos da formação de alguns partidos e aqueles existentes atualmente.

Teixeira (1989) aponta ainda outros partidos com caracterização ideológica: o Partido Comunista Brasileiro (PCB), o Partido Comunista do Brasil (PCdoB), o Partido Socialista Brasileiro (PSB), entre outros. Organizados em torno de propostas especificas, estão o Partido Verde (PV) e o Partido Social Cristão (PSC). Referir-se a todos os partidos registrados ou em processo seria exaustivo, então procuramos mencionar aqueles mais presentes no cenário político.

Em 1985 chegou ao fim o regime militar e o analfabeto voltou a ter direito ao voto ${ }^{7}$. Em 1988 foi promulgada a Constituição Cidadã. Em 1989 foram realizadas eleições diretas para presidente, após muitos anos de eleições indiretas e de luta dos movimentos que culminaram com as "Diretas Já".

Entre os acontecimentos marcantes para a política do país no início do século XXI, destacam-se a vitória presidencial de Luiz Inácio Lula da Silva em 2002, a primeira vitória do PT em uma eleição para presidente, e a morte de Antônio Carlos Magalhães, figura de notável destaque no cenário baiano, por sua influência na vida política do estado, em 2007.

Após reformas e dissidências partidárias, o Brasil conta hoje com 32 partidos políticos registrados.

No que se refere aos partidos políticos que abrigam mais políticos com terras, a Tabela 1 mostra os partidos que acolhem mais prefeitos (eleitos em 2008) e parlamentares (deputados estaduais, federais e senadores, eleitos em 2010) proprietários de terras. Entre os prefeitos, o PSDB lidera o ranking com $21 \%$ do total de 1,16 milhão de hectares declarados em 2008. Já entre os parlamentares, o PMDB tem $21 \%$ do total de hectares: 95 mil em relação ao total de 451 mil (Castilho, 2012). Em uma comparação simples, tem-se os políticos "filhos do MDB" (PSDB e PMDB) ainda mais prósperos que os “filhos da Arena” (PR, PP e DEM) no que se refere às propriedades rurais (Castilho, 2012).

Em 1824, durante o Império, os analfabetos que tivessem mais de 25 anos e que ganhassem mais de 100 mil réis, por ano, podiam votar. Já em 1846, para ter direito ao voto a renda exigida subiu para 200 mil réis por ano. Em 1882, novos eleitores analfabetos não podiam ser votados. Em 1889, já na República, acabou a exigência de renda e a idade mínima passa a ser 21 anos. Em 1891, os analfabetos perdem o direito ao voto, para recuperá-lo apenas em 1985. 
Figura 2 - Processo de formação dos principais partidos políticos no Brasil

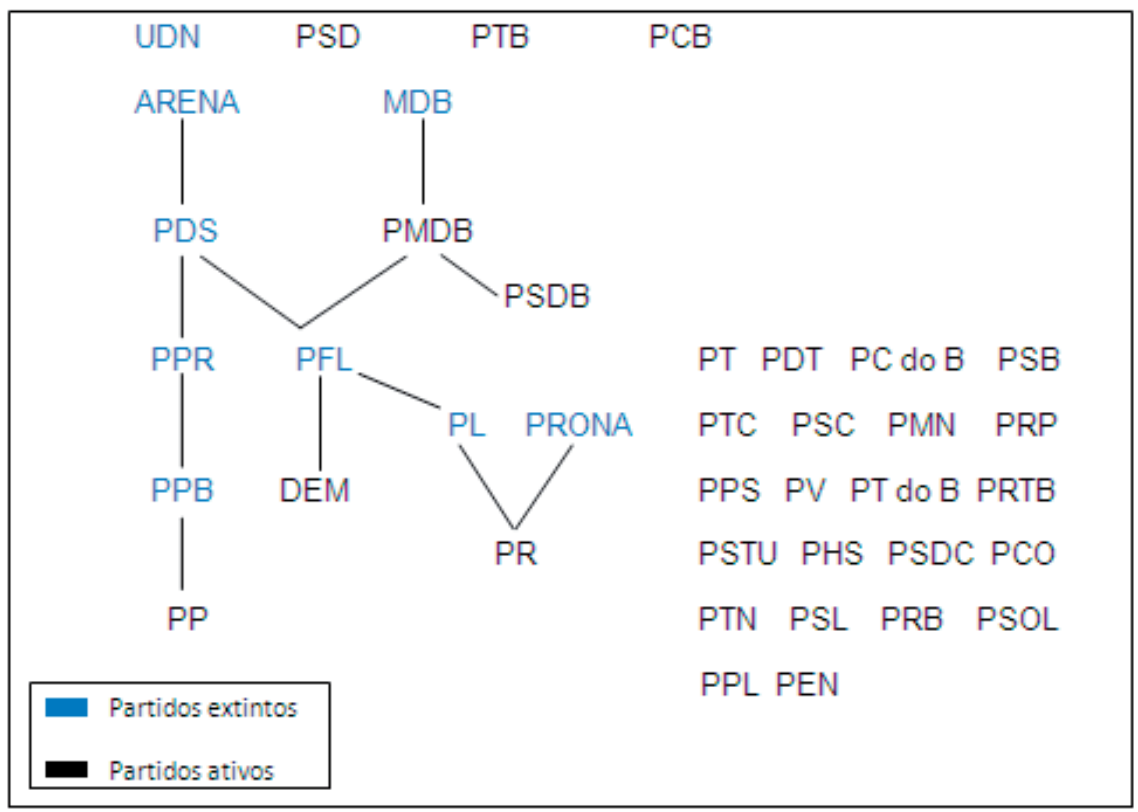

Elaboração própria.

Tabela 1 - Hectares por partido

\begin{tabular}{|c|c|c|c|c|}
\hline partido & \multicolumn{2}{|l|}{ prefeitos } & \multicolumn{2}{|c|}{ parlamentares } \\
\hline PMDB & $231.891,68$ & $19,98 \%$ & $95.201,58$ & $21,1 \%$ \\
\hline PSDB & $246.638,75$ & $21,25 \%$ & $42.774,43$ & $9,48 \%$ \\
\hline$P R$ & $151.987,79$ & $13,09 \%$ & $69.571,78$ & $15,42 \%$ \\
\hline PP & $145.121,60$ & $12,50 \%$ & $22.003,24$ & $4,88 \%$ \\
\hline DEM & $81.252,98$ & $7,00 \%$ & $84.450,07$ & $18,71 \%$ \\
\hline PDT & $64.070,09$ & $5,52 \%$ & $45.702,32$ & $10,13 \%$ \\
\hline PTB & $70.888,29$ & $6,11 \%$ & $22.097,20$ & $4,9 \%$ \\
\hline PT & $60.659,99$ & $5,23 \%$ & $7.548,87$ & $1,67 \%$ \\
\hline PPS & $46.806,68$ & $4.03 \%$ & $5.423,53$ & $1,2 \%$ \\
\hline PSB & $16.313,70$ & $1.41 \%$ & $18.879,55$ & $4,18 \%$ \\
\hline Total & $1.160 .422,88$ & & $451.269,69$ & \\
\hline
\end{tabular}

Fonte: Castilho (2012). 
A trajetória político-partidária dos municípios do TVC, assim como a do Brasil, é marcada por bruscas interrupções, sobretudo nos períodos ditatoriais, a partir da imposição de medidas coercitivas do governo. As primeiras eleições no território ocorreram em 1947. Para tratar dessa trajetória, foi feito um levantamento de dados junto ao Tribunal Regional Eleitoral da Bahia (TRE-BA) dos parlamentares eleitos desde as primeiras eleições até os dias atuais. Com base nele, foi criada uma linha do tempo ${ }^{8}$ com os prefeitos eleitos de cada município do TVC com todas as eleições regulamentadas de que dispõe o TRE-BA. Para fins de análise, são abordados neste texto apenas aqueles municípios com trajetória política mais peculiar, com destaque para Riacho de Santana.

O município de Bom Jesus da Lapa apresenta um cenário político heterogêneo. Destacam-se o $\mathrm{PR}$, a Arena e o PMDB, que se mantêm no poder por mais tempo, como partidos dominantes ao longo da história político-partidária municipal.

Brotas de Macaúbas teve a trajetória política com maior presença da Arena e ainda com a alternância entre o PFL e o PL. No entanto, na última eleição ocorreu uma mudança de cenário e um prefeiturável do PT venceu a eleição, após cinco mandatos consecutivos de gestão do PFL/PL no poder.

Embora as mulheres passam votar e serem votadas desde 1932, em toda a trajetória eleitoral do TVC, apenas três mulheres foram eleitas. A primeira prefeita foi eleita em Igaporã, em 1966. Nas últimas eleições, de 2004 e 2008, Carinhanha e Matina - município que tem uma história político-partidária marcada por três reeleições, desde as primeiras eleições realizadas, ou seja, o poder só esteve nas mãos de três pessoas até hoje -, têm a reeleição de duas mulheres, Francisca Alves Ribeiro (PT) e Olga Gentil de Castro Cardoso (PCdoB). A primeira era candidata da oposição de Carinhanha desde 2000 e em 2004 se elegeu com mais de 50\% dos votos válidos, depois de quatro mandatos marcados por prefeitos do PFL. Já a segunda concorreu às eleições de 2004 pelo $\mathrm{PTC}$ e à reeleição pelo $\mathrm{PCdoB}$.

Refletindo a predominância de apenas alguns grupos políticos no poder nos municípios baianos, Riacho de Santana é um claro exemplo da trajetória político-partidária no TVC. O município tem um histórico de reeleições muito elevado, com prefeituráveis chegando a até quatro mandatos, conforme a Figura 3.

Na linha do tempo, os prefeitos reeleitos são destacados em negrito e com realce. Para fins de análise, apenas a linha do tempo de Riacho de Santana será apresentada neste artigo. Não se considerou o grau de parentesco de parlamentares eleitos. 
Pode-se dizer que desde as primeiras eleições, praticamente quatro legendas alternaram o poder em Riacho de Santana: PSD, Arena, PFL e PMDB, mesmo com as coligações. Preliminarmente, sem uma análise minuciosa acerca do grau de parentesco entre os prefeitos, infere-se que há mais de sessenta anos havia a predominância de três famílias no poder: Cardoso de Castro, Laranjeiras e Coutinho, sendo esta última a única com dois candidatos distintos no poder, Arnaldo Cardoso Coutinho (PSD) e Alcides Cardoso Coutinho (Arena). Dessa forma, nota-se que Riacho de Santana ao longo de sua história político-partidária presenciou uma pífia alternância de poder.

Figura 3 -Riacho de Santana: cronologia político-partidária dos prefeitos eleitos

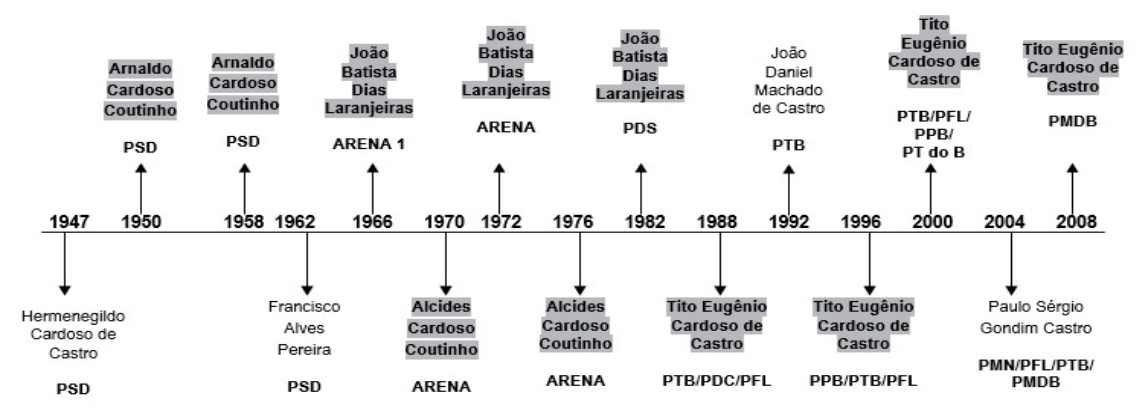

Elaboração própria.

O processo eleitoral nos municípios do TVC traz em seu bojo alianças e coligações. Em alguns momentos, nota-se que partidos com ideologias distintas, pelo menos na sua conformação, se unem para dar apoio e garantir a vitória de seus candidatos. Há casos em que o PMDB alia-se ao PSDB, ao PT, ao PDT e ao PFL, mostrando que, na política, muitas vezes, o que prevalece são os interesses político-partidários e os meios que podem levar ao poder.

Alguns partidos políticos foram e/ou são muito presentes na história eleitoral do TVC, lançando novos ou os mesmos candidatos a cada eleição, venciam e se mantinham no poder. A eleição de Lula para presidente do Brasil, em 2002, começa a redesenhar o quadro político do país, não somente nas capitais, mas também nas cidades do interior. Parlamentares do PT, fortalecidos pela vitória do presidente, entram em cena. E é a partir das eleições de 2004 que os municípios do território começam a ter prefeitos eleitos de partidos diferentes dos de costume (PSDB, PMDB, PL e PFL), marcantes no interior. 
Depois da eleição e da reeleição de Lula, o PT fortaleceu-se em Brotas de Macaúbas, Feira da Mata, Morpará e Paratinga com a vitória de prefeituráveis petistas na eleição de 2008.

A presença do PFL por anos consecutivos nas prefeituras de municípios do TVC e da Bahia como um todo demonstra a grande influência que Antônio Carlos Magalhães (ACM) exercia sobre o Estado. Sua morte, em 2007, também contribuiu para mudar o cenário político baiano. A família Magalhães, que exercia forte influência no interior, passa a perdê-la, não obstante muitos de seus membros se mantenham na política, contudo, sem o mesmo prestígio da época de seu patriarca. Assim, já se começa a perceber uma tendência para o preenchimento da "lacuna política" deixada pelo "homem forte baiano” em 2009 por Geddel Vieira Lima (PMDB) - deputado e então ministro da Integração Nacional, mas com contornos estratégicos diferentes dos praticados pelo senador. No entanto, nas eleições para governador, em 2010, Geddel foi o terceiro menos votado, e Jaques Wagner (PT), reeleito. As eleições de 2012 trouxeram a família Magalhães de volta aos holofotes baianos com a candidatura e a eleição de ACM Neto (DEM) à prefeitura de Salvador, ainda que ele, ao longo de sua carreira política como deputado federal, não tenha estado muito presente no cenário político local.

\section{Poder político e propriedade da terra no Território do Velho Chico}

Para verificar a relação existente entre os prefeitos e os proprietários de terras no TVC e apontar a possível relação entre poder político e propriedade da terra, levantamos dados do Instituto Nacional de Colonização e Reforma Agrária (INCRA), da Junta Comercial do Estado da Bahia (JUCEB) e do Tribunal Superior Eleitoral (TSE).

Para identificar os grandes proprietários, utilizamos uma lista fornecida pelo Incra. As propriedades constantes na relação do órgão são aquelas com área superior a 10 mil hectares. Dos proprietários listados, doze são pessoas físicas e 22, pessoas jurídicas, inclusive sete firmas registradas em outros estados. Foi necessário, assim, contatar a JUCEB para identificar as pessoas físicas que haviam registrado as propriedades.

A partir do cruzamento de prefeitos com proprietários, de acordo com os dados do INCRA (os nomes encontrados não podem ser citados), não foi possível constatar relação entre os prefeitos eleitos do TVC e propriedades com mais de 10 mil hectares, mas com áreas menores, de dez a mil hectares, sim. 
O histórico do TVC é de concentração de terras, com mais de 50\% do território pertencente à categoria de "forte a muito forte". A maioria dos imóveis rurais no TVC é considerada minifúndio ou pequena propriedade e pertence a um grande número de proprietários, enquanto a minoria dos proprietários detém as maiores áreas de terras. Dessa forma, a presença de áreas de mil hectares na região só ratifica a presença da elevada concentração e demonstra o quão importante é deter tal extensão de terra no território.

$\mathrm{Na}$ declaração de bens dos candidatos eleitos, prefeitos e vice-prefeitos, do TSE, havia uma limitação dos dados, já que o tribunal só disponibiliza a declaração da última eleição realizada, ou seja, a de 2008. Outra ressalva a se fazer é que os dados do TSE são declarados pelos próprios candidatos. Apesar de a declaração apresentar a descrição dos bens que o candidato possui, utilizamos apenas aqueles referentes à posse da terra, isto é, as propriedades rurais. Dos prefeitos eleitos na eleição de 2008, aproximadamente 56\%, (Quadro 3) possuem propriedade rural dentro e fora de seus municípios. $\mathrm{O}$ tamanho das propriedades varia de dez a mais de mil hectares, ratificando a presença de proprietários ${ }^{9}$ de terras na região e constatando que muitos são políticos.

Os prefeitos de Barra, Ibotirama e Paratinga apresentam as maiores áreas de terras do TVC: 971, 801 e 768 hectares, respectivamente. Bom Jesus da Lapa, Malhada e Riacho de Santana têm prefeitos proprietário de terras - sem localidade e área informadas, porém. Há prefeitos com propriedades dentro e fora de seus municípios, e, mesmo assim, as últimas estão localizados no próprio TVC.

Os prefeitos de Carinhanha, Feira da Mata, Igaporã, Morpará, Muquém do São Francisco, Oliveira dos Brejinhos e Sítio do Mato não possuem propriedades rurais declaradas.

Dos vice-prefeitos, $50 \%$ são proprietários de terras. Nos municípios em que não há prefeitos donos de imóveis, os vices são proprietários. Os vice-prefeitos eleitos de Igaporã, Muquém do São Francisco e Sítio do Mato apresentam extensas áreas de terras não só município em que venceram as eleições, mas em outras cidades vizinhas que fazem parte do TVC. Em Igaporã e Malhada, os vice-prefeitos possuem terras de valores elevados; no entanto, não informaram sua localidade nem sua área.

De acordo com a Lei 8.629 de 23 de fevereiro de 1993, o imóvel rural classifica-se em: pequena propriedade, um a quatro módulos fiscais; média propriedade, quatro a quinze módulos fiscais; e grande propriedade, maior que quinze módulos fiscais (Brasil, 1993). 
Quadro 3 - Declaração de imóveis rurais dos prefeitos e vice-prefeitos eleitos (TVC, 2008)

\begin{tabular}{|c|c|c|c|c|c|c|c|}
\hline \multirow[t]{3}{*}{ município ${ }^{10}$} & \multirow[t]{3}{*}{ partido } & \multicolumn{6}{|c|}{ terras } \\
\hline & & \multicolumn{2}{|c|}{ no município } & \multicolumn{2}{|c|}{ fora do município } & \multicolumn{2}{|c|}{ localidade não informada } \\
\hline & & ha & $\mathrm{R} \$$ & ha & $\mathrm{R} \$$ & ha & $\mathrm{R} \$$ \\
\hline \multicolumn{8}{|c|}{ Barra } \\
\hline prefeito & PP & 971 & $10.000,00$ & - & - & - & - \\
\hline vice-prefeito & PDT & - & - & s.i. ${ }^{*}$ & $33.431,58$ & - & - \\
\hline \multicolumn{8}{|c|}{ Bom Jesus da Lapa } \\
\hline prefeito & PMDB & - & - & - & - & s.i. & $150.000,00$ \\
\hline vice-prefeito & PT & - & - & - & - & - & - \\
\hline \multicolumn{8}{|c|}{ Brotas de Macaúbas } \\
\hline prefeito & PT & 70,3 & $48.369,00$ & - & - & - & - \\
\hline vice-prefeito & PT & - & - & - & - & - & - \\
\hline \multicolumn{8}{|c|}{ Carinhanha } \\
\hline vice-prefeito & PTB & 3.600 & $367.000,00$ & 155 & $15.000,00$ & - & - \\
\hline \multicolumn{8}{|c|}{ Feira da Mata } \\
\hline vice-prefeito & PSC & 75 & $75.000,00$ & - & - & - & - \\
\hline \multicolumn{8}{|c|}{ Ibotirama } \\
\hline prefeito & PMDB & 801 & $50.000,00$ & - & - & - & - \\
\hline vice-prefeito & DEM & 12 & $17.172,17$ & 600 & $143.102,60$ & - & - \\
\hline \multicolumn{8}{|c|}{ Igaporã } \\
\hline prefeito & PR & - & - & - & - & - & - \\
\hline vice-prefeito & $\mathrm{PCd} 0 \mathrm{~B}$ & - & - & - & - & s.i. & $900.000,00$ \\
\hline \multicolumn{8}{|c|}{ Malhada } \\
\hline prefeito & PMDB & - & - & - & - & s.i. & $138.090,00$ \\
\hline vice-prefeito & PPS & - & - & - & - & s.i. & $192.291,00$ \\
\hline \multicolumn{8}{|c|}{ Matina } \\
\hline prefeito & $\mathrm{PCd} 0 \mathrm{~B}$ & 30 & $30.000,00$ & 213 & $80.000,00$ & - & - \\
\hline \multicolumn{8}{|c|}{ Morpará } \\
\hline vice-prefeito & $\mathrm{PCd} 0 \mathrm{~B}$ & 56 & $30.000,00$ & - & - & - & - \\
\hline \multicolumn{8}{|c|}{ Oliveira dos Brejinhos } \\
\hline vice-prefeito & PMDB & s.i. & $150.000,00$ & - & - & - & - \\
\hline \multicolumn{8}{|c|}{ Paratinga } \\
\hline prefeito & PT & 768 & $150.000,00$ & - & - & - & - \\
\hline vice-prefeito & PT & - & - & - & - & - & - \\
\hline \multicolumn{8}{|c|}{ Riacho de Santana } \\
\hline prefeito & PMDB & - & - & 1.100 & $300.000,00$ & 110 & $100.000,00$ \\
\hline vice-prefeito & PSDB & 110 & $110.000,00$ & 5.759 & $430.000,00$ & - & - \\
\hline \multicolumn{8}{|c|}{ Serra do Ramalho } \\
\hline prefeito & $\mathrm{PCd} 0 \mathrm{~B}$ & 60 & $170.000,00$ & - & - & - & - \\
\hline vice-prefeito & PT & 10 & $25.000,00$ & - & - & - & - \\
\hline
\end{tabular}

* Sem informação.

Elaboração própria, baseado em dados do TSE, 2009. 
No município de Carinhanha, o vice-prefeito possui somente dentro da cidade 3.600 hectares de terras, além de efetivo de bovinos; o de Ibotirama, 600; e o de Riacho de Santana, 5.759 hectares - significativas áreas de terras.

A análise dos dados mostra que existe relação entre o poder político e a posse da terra no TVC. Contudo, cumpre realizar novo levantamento de dados não só de prefeitos, como foi o foco do estudo, mas também de outros cargos, como vereadores, deputados federais e estaduais e, talvez, até senadores e governador. ${ }^{10}$

Os dados do Quadro 3 evidenciam certa incoerência dos dados declarados. Propriedades com áreas menores apresentam valores mais elevados que áreas de grandes extensões. O prefeito de Barra possui 971 hectares de terra, avaliados em R $\$ 10$ mil, enquanto o de Serra do Ramalho tem 60 hectares, avaliados em R 170 mil, por exemplo. Logo, a declaração de bens sugere que haja erros nos dados, devendo ser realizado um acompanhamento detalhado por parte do serviço público para apurar a veracidade do que é declarado. Também pode haver, além dos bens (imóveis rurais) elencados, o registro de propriedades em nome de outras pessoas, como "laranjas".

Como o TVC tem uma extensa área rural, é notória a possibilidade de alguns proprietários de terras serem também políticos. Dessa forma, quem determinará o poder e exercerá maior domínio na região de estudo são aqueles que detêm maiores extensões de terras. Através da Lei 8.629/1993, pode-se observar como estão classificados os imóveis rurais dos prefeitos e vice-prefeitos do TVC. Os prefeitos de Barra, Ibotirama e Paratinga têm suas terras classificadas como média propriedade, superiores a quatro módulos fiscais ${ }^{11}$. Já as propriedades do prefeito de Riacho de Santana são classificadas como grande propriedade, superiores a quinze módulos fiscais. Os vice-prefeitos de Carinhanha e Riacho de Santana têm imóveis classificados como grande propriedade - esse município é, de fato, um caso peculiar: além de seu atual prefeito estar no quarto mandato, totalizando dezesseis anos no poder, também é um grande proprietário de terras,

10 Os prefeitos dos municípios de Carinhanha (PT), Feira da Mata (PT), Morpará (PT) e Oliveira dos Brejinhos (PMDB), o vice-prefeito de Matina (PP) e os prefeitos e vice-prefeitos de Muquém do São Francisco (PMDB e PDT) e Sítio do Mato (PDT e PT) não tiveram registro de posse de terras identificado.

1 O módulo fiscal do TVC corresponde a 65 hectares de terras. Para calcular a classificação da propriedade de um proprietário do TVC, divide-se sua área (em hectares) por 65. Os valores encontrados em módulos fiscais indicam se a propriedade é classificada como pequena (um a quatro módulos fiscais), média (de quatro a quinze módulos fiscais) ou grande (maior que quinze módulos fiscais). 
o que ratifica a relação entre o poder político e a propriedade da terra no TVC de que trata este artigo. Tal fato expressa mais claramente quem exerce o poder em regiões onde a terra é tão concentrada. Todavia, cumpre ressaltar que como os municípios do TVC concentram suas atividades mais nos setores de serviços e agropecuário, não desempenhando muitas atividades ligadas à indústria ou a qualquer outra oportunidade de investimento, a terra (passaporte para o proprietário de terras virar empresário) e sua extensão são de grande importância no contexto do desenvolvimento local, da mensuração de riqueza e, por conseguinte, do poder.

\section{Considerações finais}

O processo histórico de ocupação do território, tanto no âmbito nacional como no regional, criou uma das estruturas de propriedade mais concentradas do mundo, que por sua vez vem acompanhada de grandes desigualdades sociais, ao manter uma massa de agricultores sem terra para cultivar. Para reverter esse quadro, deve-se fazer com que a utilização das terras no Brasil se realize em benefício principalmente daqueles que nela trabalham, e não se constitua apenas num negócio de uma minoria. Para que isso ocorra, não é suficiente esperar o desenrolar natural e espontâneo dos fatos: é preciso utilizar algum meio para reverter a situação em que vivem milhões de agricultores.

O problema premente do Brasil é o da reforma agrária, considerando tanto diversificar a produção e comprometê-la com o mercado interno como garantir a fixação do homem ao campo, atenuando o êxodo rural. Uma reforma agrária deve estar voltada para a democratização do acesso a terra, por parte do trabalhador rural, e para a orientação do que produzir, de como produzir e do destino que deve ser dado à produção. Ela deve atingir igualmente as formas e as funções da produção. A divisão da terra e o amparo ao pequeno proprietário e produtor devem estar conjugados.

O que também se espera de uma política de reforma agrária é que possa gerar um impacto significativo sobre as relações de poder em vigor no campo brasileiro, superando a estrutura responsável pela manutenção de uma sociedade injusta e extremamente desigual.

A relação do poder político com a propriedade da terra no TVC é um fato e comprova o domínio da propriedade da terra nas mãos de poucos. 
Vale ressaltar, no que diz respeito à concentração de terras, que a atual política de desenvolvimento territorial da Bahia não inclui a questão da apropriação do território em suas propostas. A permanência de características do passado, oriundas do coronelismo, ainda é presente em alguns municípios do TVC. A manutenção do poder agora é retratada através da figura do político e grande proprietário de terras, sem esquecer que a relação do poder local também adquire novas configurações - entre elas, a manifestação do poder político no direito de propriedade. Logo, um controle maior do serviço público por meio do acompanhamento das ações dos governantes se faz necessário no território.

Garantido o acesso a terra, outro grande desafio do campo seria a inserção dos pequenos agricultores - os familiares - no mercado, além da definição de como isso aconteceria e de como se apropriaria da produção. Trata-se de um desafio que poderia ser vencido com o auxílio do cooperativismo, do associativismo, do crédito associado à assistência técnica comprometida e coerente com os princípios produtivos da agricultura familiar. Isso significaria uma verdadeira revolução no campo, que deve passar primeiramente pelo processo equitativo de distribuição da propriedade da terra.

\section{Referências}

ABRAMOVAY, Ricardo \& BEDUSHI FILHO, Luiz Carlos (2004). "Desafios para o desenvolvimento das regiões rurais". Nova Economia, v. 14, n. 3, p. 35-70.

ALMEIDA, Francisco Provázio Lara de (2009). "Abuso do direito de propriedade e a função social da posse: a necessidade de rever a ponderação de interesses constitucionais". Jus Navigandi, n. 2034. Disponível em: http:// jus.com.br/artigos/12251. Acesso em 16 maio 2011.

ANDRADE, Manuel Correia de (2002). "Espaço agrário brasileiro: velhas formas, novas funções, novas formas, velhas funções". Espaço e Tempo, n. 12, p. 11-9.

CONFERÊNCIA DE CULTURA (2011). Mapa do Velho Chico. Disponível em: http://conferenciadecultura.files.wordpress.com/2011/10/mapa-velho-chico.jpg. Acesso em 16 out. 2011.

BRASIL (1964). Lei n. 4.504, 30 nov. Disponível em: http://www.planalto. gov.br /CCIVIL_03/leis/L4504.htm. Acesso em 16 jun. 2008. 
BRASIL (1988). Constituição Federal. Disponível em: http://www.planalto. gov.br/ccivil_03/constituicao/constituicaocompilado.htm. Acesso em 29 mar. 2009.

BRASIL (1993). Lei n. 8.629, 25 fev. Disponível em: http://www.planalto.gov. br /ccivil_03/leis/18629.htm. Acesso em 16 jun. 2009.

BURSZTYN, Marcel (1984). O poder dos donos: planejamento e clientelismo no Nordeste. Petrópolis (RJ): Vozes.

CANCIAN, Renato (2007). "Estado do bem-estar social: história e crise do welfare state" UOL Educação, 29 maio. Disponível em: http://educacao. uol.com.br/disciplinas/sociologia/estado-do-bem-estar-social-historia-e-crise-do-welfare-state.htm. Acesso em 3 jul. 2014.

GERMANI, Guiomar Inez (2006). "Condições históricas e sociais que regulam o acesso a terra no espaço agrário brasileiro”. Geotextos, v. 2, n. 2m, p. 115-47.

GERMANI, Guiomar Inez; OLALDE, Alícia Ruiz \& OLIVEIRA, Gilca Garcia (2006). Acesso a terra e desenvolvimento territorial no Médio São Francisco (BA). Salvador: MGEO, GeografAR, UFBA.

HACKBART, Rolf (2008). Função social da propriedade no Brasil. Brasília: Ministério de Desenvolvimento Agrário, Instituto Nacional e Colonização e Reforma Agrária.

IBGE (2010). Censo demográfico 2010 [online]. Disponível em: http://www. ibge.gov.br/home/estatistica/populacao/censo2010. Acesso em 29 mar. 2012.

LEAL, Victor Nunes (1976). Coronelismo, enxada e voto: o município e o regime representativo no Brasil. 2. ed. São Paulo: Alfa-Omega.

LIMA, Ruy Cirne (2002). Pequena história territorial do Brasil: sesmarias e terras devolutas. 5. ed. Goiânia: Editora UFG.

CÂMARA, Lourival (1949). "A concentração da propriedade agrária no Brasil”. Boletim Geográfico, v. 7, n. 77, p. 516-28.

CASTILHO, Alceu Luís (2012). Partido da terra: como os políticos conquistam o território brasileiro. São Paulo: Contexto.

PRADO JR., Caio (1979). A questão agrária no brasil. São Paulo: Brasiliense.

PROJETO GEOGRAFAR (2008). Evolução histórica do índice de Gini. TVC, 1920-1996. Salvador: Geografar/UFBA. Disponível em: http://www. geografar.ufba.br. Acesso em 29 mar. 2011. 
SAUER, Sérgio \& PEREIRA, João Márcio Mendes (2006). Capturando a terra: Banco Mundial, políticas fundiárias neoliberais e reforma agrária de mercado. São Paulo: Expressão Popular.

SOUZA, Alírio Fernando Barbosa de (1998). O coronelismo no Médio São Francisco: um estudo de poder local. Salvador: Microtextos Edições Gráficas.

TAGLIETTI, Dablio Batista (2005). "A natureza social e econômica da Lei de Terras de 1850". Revista de Ciências Humanas, v. 6, n. 7, p. 189-205. TEIXEIRA, Celso Elenaldo (1989). "Partidos políticos: fragmentação e crise". Caderno do CEAS, n. 122, p. 22-34.

\section{Resumo}

Este artigo estuda o Território de Identidade do Velho Chico (TVC), no semiárido baiano, região que é um claro exemplo da concentração de terras no Estado. $\mathrm{O}$ trabalho busca analisar a apropriação das terras nas mãos de poucos desde os primórdios da ocupação do território nacional e sua continuidade nos períodos atuais, garantindo e fortalecendo a concentração fundiária. Procura entender, também, a relação entre a propriedade da terra - como instrumento de poder regional - e o poder político, além de verificar se ao longo do tempo a concentração de terras na região garantiu a centralização do poder, percebendo a unicidade da questão e enfocando a desigualdade e a exclusão.

Palavras-chave: concentração fundiária, propriedade da terra, poder político, desigualdade.

\section{Abstract}

This work studies the Territory of the Old São Francisco River (Território de Identidade do Velho Chico, TVC), in Bahia's semi-arid region. It seeks to analyze appropriation of land by a few hands since the beginning of the occupation of Brazil's territory and its continuity in current times, ensuring and strengthening land concentration. It also seeks to understand the relationship between land ownership - as an instrument of regional power - and political power, as well as to examine whether land concentration in the region ensured centralization of power over time, understanding the connection between the issues and focusing on inequality and exclusion.

Keywords: land concentration, land ownership, political power, inequality.

Recebido em 24 de maio de 2014.

Aprovado em 29 de agosto de 2014. 